\title{
ANÁLISE DE DISTORÇÕES RADIOMÉTRICAS DE IMAGENS DA CÂMERA TETRACAM ADC LITE
}

\author{
ANALYSIS OF THE RADIOMETRIC DISTORTIONS OF THE TETRACAM ADC LITE CAMERA
}

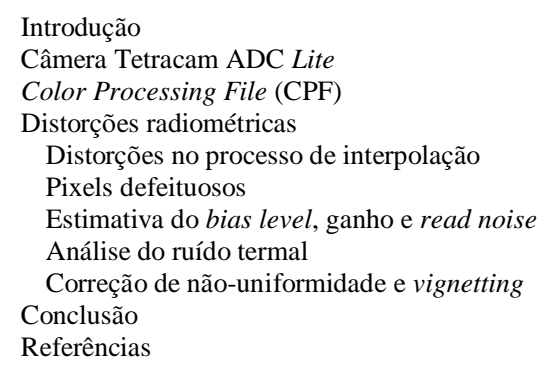

Thiago STATELLA, Roberto Nunes Vianconi SOUTO, Robson Rogério Dutra PEREIRA

Instituto Federal de Educação, Ciência e Tecnologia de Mato Grosso - IFMT, Campus Cuiabá. Rua Profa. Rua Zulmira Canavarros, 95, Cuiabá-MT.Email: t.statella@gmail.com; roberto.souto@cba.ifmt.edu.br; robson.pereira@cba.ifmt.edu.br

RESUMO - Muitos trabalhos executados com Aeronaves Remotamente Pilotadas (ARP) tem se valido da utilização da câmera multiespectral ADC Lite da fabricante Tetracam. As imagens produzidas pela câmera são analisadas e interpretadas qualitativamente e quantitativamente sem que se tenha procedido à correção de distorções radiométricas das mesmas, tarefa que o rigor científico exige para que qualquer conclusão resultante tenha validade prática e acadêmica. Neste trabalho ficou demonstrado que distorções tais como read noise, não-uniformidade de resposta dos pixels à radiância proveniente dos alvos e vignetting estão presentes nas imagens. Para além destas, os pesos do arquivo de interpolação do filtro de Bayer fornecidos pela Tetracam produzem resultados incorretos em muitos casos, ocasionando a perda de informação, particularmente na banda do Vermelho, com frequências significativas $\left(\sim 10^{5}\right)$ de pixels com valores saturados para preto. A correção de todos estes efeitos e de artefatos remanescentes, nas bordas das imagens, do processo de interpolação dos valores de brilho, é imprescindível para que se possa trabalhar com as imagens, tal qual demonstra-se neste artigo, por meio da comparação de índices obtidos da razão de bandas a partir das imagens com e sem distorções.

Palavras-chave: Tetracam ADC Lite; Distorções radiométricas; Câmera multiespectral.

ABSTRACT - A number of works using Unmanned Aerial Vehicles (UAV) have been taking advantage of the ADC Lite multispectral camera by Tetracam. The images acquired by the camera have been qualitatively and quantitatively analyzed by many authors without previously correcting radiometric distortions, which is mandatory for practical and academic purposes. In this paper we made it clear that distortions such as the read noise, pixels non-uniform response to the incoming radiance and the vignetting effect are present in the ADC images. Beside these distortions, the weighting values in the Color Processing File (CPF), provided by Tetracam and used to interpolate the Bayer filter, delivers wrong bright values in a number of situations, causing information loss, particularly in the Red band, producing very high frequencies $\left(\sim 10^{5}\right)$ of black saturated pixels. The correction of these effects and remaining noise artifacts in the image frame (caused by the color interpolation) is mandatory when working with them, which is clearly demonstrated in this paper when we calculated a normalized band ratio from the raw and corrected images.

Keywords: Tetracam ADC Lite; Radiometric distortions; Multiespectral câmera.

\section{INTRODUÇÃO}

A câmera ADC Lite da fabricante Tetracam é uma versão mais leve da câmera ADC Air. Por ser mais leve, a ADC Lite tem sido amplamente utilizada em conjunto com diversos tipos de Aeronaves Remotamente Pilotadas (ARP) em aplicações diversas e, especialmente, na área de agricultura (Aguerra et al., 2011; Primicerio et al., 2012; Gehrke \& Greiwe, 2013; Matese et al., 2015; Vega et al., 2015; Xavier et al., 2019).

A ADC Lite possui um sensor do tipo CMOS (Complementary Metal-Oxide Semiconductor) único, em arranjo matricial (1.536 x 2.048 pixels). A resolução espectral da câmera é de três bandas: Verde $(\sim 0,52-0,60 \mu \mathrm{m})$, Vermelho $(\sim 0,63-0,69 \mu \mathrm{m})$ e Infravermelho Próximo ( 0,76-0,90 $\mu \mathrm{m})$, cujos intervalos espectrais são aproximadamente os mesmos do sensor TM (Thematic Mapper) a bordo do satélite Landsat5. Para obtenção das bandas espectrais a câmera é equipada com um filtro padrão Bayer e, portanto, requer uma interpolação dos números digitais (ND) para estimativa de brilho dos pixels sem informação em cada um dos canais.

As imagens geradas pela ADC são acometidas de distorções radiométricas, causadas, dentre outras fontes, pelo próprio sistema sensor, advindos de sua eletrônica ou sistema de lentes (Gonzalez \& Woods, 2007; Richards, 2013). 
Dentre estas distorções, podem ser citadas aquelas relacionadas ao ruído de leitura (readout noise), ruídos termais (dark current), pixels e linhas defeituosas e variações na função de ganho entre detectores (flat fielding).

Além disso, o arquivo de processamento de cores (Color Processing File), fornecido para a câmera, e que guarda os parâmetros utilizados na interpolação do filtro de Bayer para geração das bandas do Verde, Vermelho e Infravermelho Próximo, tem produzido resultados incorretos à medida em que muitos valores de pixels são saturados (recebem valor preto ou branco) no processo, ocasionando perda significativa de informação.

Estas distorções fazem com que a radiância registrada para cada pixel da imagem não corresponda à emitância da área correspondente no terreno, excetuados fatores como espalhamento e absorção atmosférica, ângulo sólido e geometria de visada. Para que se possam extrair informações relevantes de imagens multiespectrais, tais como índices de vegetação, os quais fornecem uma medida do vigor vegetal e podem indicar desiquilíbrios hídrico, nutricional ou, ainda, infestação por pragas, em lavouras de algodão, soja, etc., é imprescindível que as imagens passem por correções radiométricas. Do contrário, qualquer análise sobre os dados brutos estará comprometida e perderá qualquer valor científico.

$\mathrm{O}$ presente artigo tem como objetivo, portanto, a análise de distorções radiométricas presentes nas imagens adquiridas pelo sensor CMOS da câmera ADC Lite da Tetracam, bem como estimar correções para os ruídos de leitura, vignetting, não-uniformidade da resposta dos pixels no plano do sensor e para distorções ocorridas no processo de interpolação dos níveis de brilho (ND) do filtro de Bayer.

\section{CÂMERA TETRACAM ADC LITE}

A câmera ADC Lite da Tetracam possui um sensor do tipo CMOS (Complementary MetalOxide Semiconductor) único, em arranjo matricial (1.536 x 2.048 pixels). A resolução espectral da câmera é de três bandas: Verde $(\sim 0,52-0,60 \mu \mathrm{m})$, Vermelho $(\sim 0,63-0,69 \mu \mathrm{m})$ e Infravermelho Próximo $\quad(\sim 0,76-0,90 \mu \mathrm{m})$, cujos intervalos espectrais são aproximadamente os mesmos do sensor TM (Thematic Mapper) a bordo do satélite Landsat-5. Para obtenção das bandas espectrais a câmera é equipada com um filtro padrão Bayer e, portanto, requer uma interpolação dos números digitais (ND) para estimativa de brilho dos pixels sem informação em cada um dos canais (Tetracam, 2019).

Esta interpolação é feita com base no arquivo de extensão CPF (Color Processing File), fornecido pela fabricante da câmera, e que contém os pesos da matriz de interpolação do filtro de Bayer. Cada modelo de câmera possui seu arquivo CPF padrão, que, em conjunto com o software proprietário Pixelwrench2 (PW2), deve ser usado para geração das composições coloridas a partir dos dados brutos capturados pelo sensor. A informação espectral do Infravermelho Próximo (IVP) é obtida adicionando-se um filtro amarelo sobre os pixels que originalmente captariam a Radiação Eletromagnética (REM) do azul. Estes pixels são então usados para medir a radiação no IVP (uma vez que o silício é sensível à REM nesta região do espectro).

A resolução radiométrica da ADC é de 10 bits (0 a 1.023 tons de cinza) em formato bruto $(R A W)$ sem compactação (nos ajustes, a câmera dispõe ainda da opção por 8 bits em formato bruto). Entretanto, o software PW2 permite a exportação de imagens apenas em 8 bits ( 0 a 255 tons de cinza), em formato TIFF.

A distância focal da câmera é fixa em $8 \mathrm{~mm}$. O foco da lente é ajustável, mas é mantido no infinito para fotos aéreas. A abertura, ou razão focal, é controlada por um anel no cone da lente, e pode variar de f/1,4 até f/16. Os parâmetros de exposição são automáticos. A resolução espacial nominal do sensor (IFOV) é de $40 \mu \mathrm{rad}$ (o sensor mede 4,92 x 6,55 mm e cada pixel mede $3,2 \times 3,2 \mu \mathrm{m})$ e a faixa imageada (FOV) mede $\sim 35^{\circ} \times 47^{\circ}$. Como exemplo, em uma altura de voo de $100 \mathrm{~m}$, os parâmetros correspondem a $40 \mathrm{~cm}$ de IFOV e $\sim 60$ x $80 \mathrm{~m}$ de FOV.

\section{COLOR PROCESSING FILE (CPF)}

As imagens brutas capturadas pela ADC precisam ser processadas no software PW2 a fim de que se executem as interpolações dos valores de brilho faltantes em cada uma das bandas (por causa do filtro de Bayer). Os pesos utilizados no processo de interpolação estão contidos em um arquivo com extensão CPF. Cada câmera possui um CPF próprio, produzido para seu modelo. Só 
após esta etapa as imagens das bandas do verde, vermelho e IVP ficam disponíveis para exportação no PW2. O arquivo $\mathrm{CPF}$ que acompanha a câmera (arquivo 220960.cpf, em que 220960 é o modelo da câmera) nem sempre produzirá resultados esperados e corretos para todo tipo de aplicação. Como exemplo, a figura 1 mostra a imagem TTC01642.TIF, composição B (banda Verde) G (banda Vermelha) R (banda IVP), adquirida sobre uma plantação experimental de algodão do Instituto Matogrossense do Algodão (IMAmt) em Primavera do Leste - MT processada com o arquivo CPF fornecido com a câmera. A região é quase totalmente ocupada por vegetação, com exceção da estrada que corta a cena em sentido longitudinal e a via de acesso à área de cultivo no centro, ambas em solo exposto. Esta área retangular, na parte central superior, é uma plantação de algodão. Fora do retângulo de cultivo, a área é recoberta por vegetação rasteira. Os pixels rotulados em amarelo foram saturados no processo de interpolação utilizando o arquivo CPF fornecido para o modelo da câmera e receberam o valor " 0 " (preto) na banda do vermelho. Apesar de o comportamento espectral da vegetação sadia exibir valores baixos de reflectância na banda do vermelho (Meneses \& Neto, 2001), causados pela absorção deste comprimento de onda por pigmentos, como clorofilas e carotenoides, valores nulos de radiância estão em desacordo com o esperado. Mesmo a presença de sobras, em casos em que a altura de voo é relativamente baixa, e a resolução espacial das imagens permite resolver pixels pertencentes a esta classe espectral, não justificaria a existência de uma frequência tão grande $\left(\sim 10^{5}\right.$ pixels) de valores nulos.

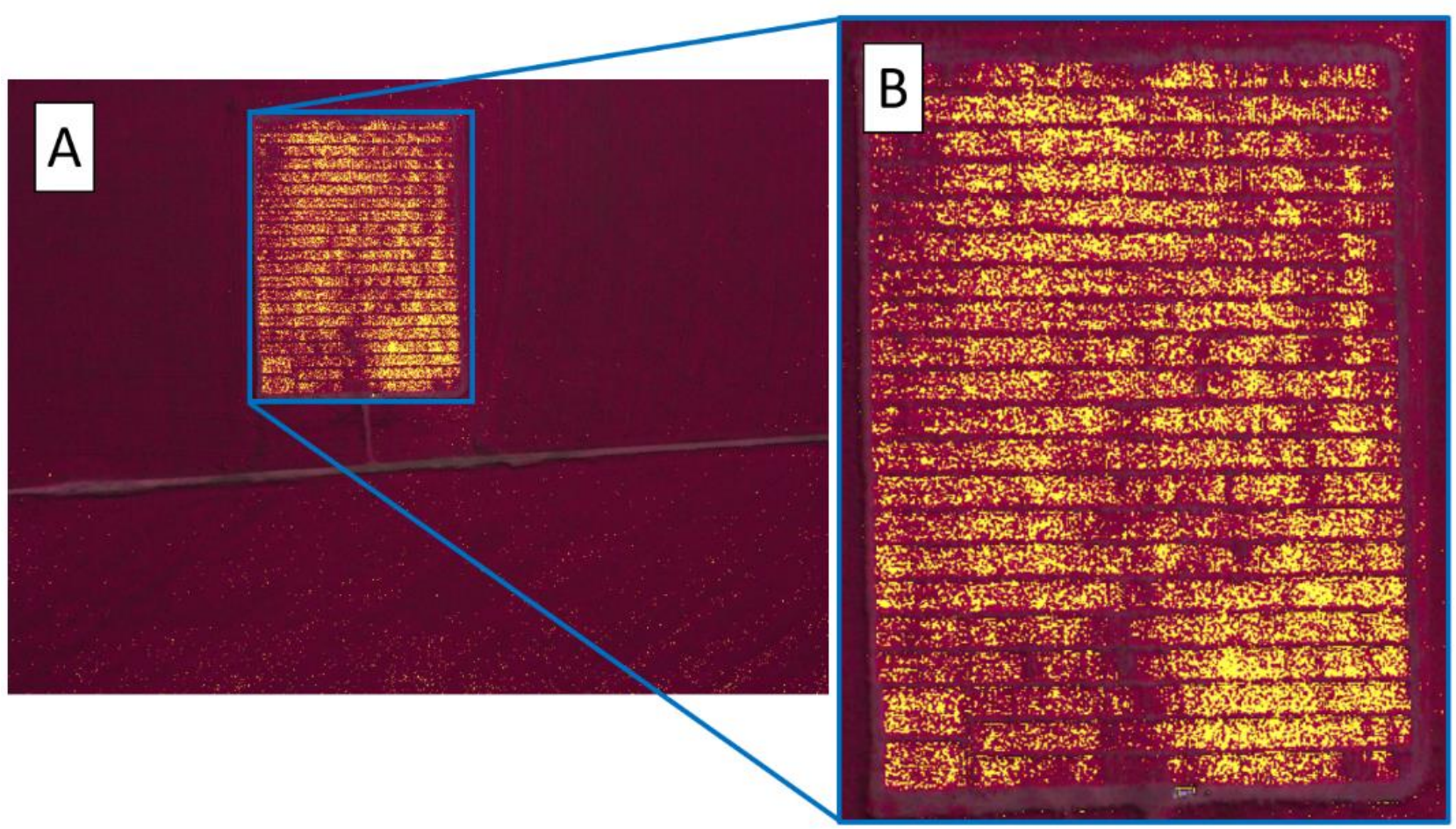

Figura 1 - Imagem TTC01642.TIF (A) processada com o arquivo CPF (220960.cpf) fornecido pela fabricante para o modelo da câmera. Em detalhe (B), campo experimental do IMA com plantação de algodão. Tanto em (A) quanto em (B) os pixels saturados para preto na banda do vermelho estão representados em amarelo.

Esse efeito indesejável pode ser visto no histograma da imagem, mostrado na figura 2, e já foi reportado por outros autores (Huang et al., 2010; Xavier et al., 2019).

Antes de se proceder às análises de distorções radiométricas causadas pelo sensor é necessária a criação de um novo arquivo CPF a fim de eliminar ou reduzir, tanto quanto for possível, o efeito indesejável da saturação excessiva de pixels na banda do Vermelho. Esta tarefa pode ser feita com auxílio do software PW2. Imagens da placa de Teflon com iluminação difusa de mesma distribuição espectral (irradiância solar hemisférica) das imagens de campo foram utilizadas para definir o novo arquivo CPF. O tempo de exposição foi ajustado de maneira que os valores médios de brilho (ND) em cada banda se aproximassem do valor médio de saída do conversor analógico/digital (A/D) que, no caso, possui resolução radiométrica de 8 bits. Após a 
criação deste novo arquivo de interpolação do filtro de Bayer, procedeu-se à investigação da melhoria no efeito de saturação, comparando-se, para isso, as frequências de pixels saturados para um conjunto de 100 imagens de campo, processadas com os dois arquivos CPF. A tabela 1 mostra os resultados obtidos. É possível perceber que a frequência de saturação para preto reduziu-se significativamente com o $\mathrm{CPF}$ criado em relação à utilização do $\mathrm{CPF}$ fornecido para o modelo da câmera.

A figura 3 exibe os histogramas das bandas do Verde, Vermelho e IVP para a mesma imagem TTC01642.TIF processada com o novo CPF.

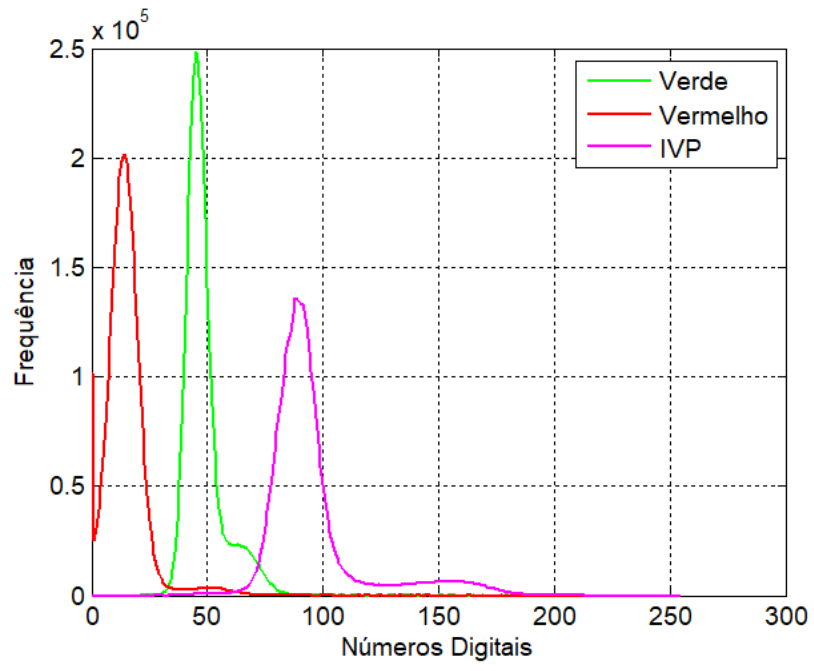

Figura 2 - Histograma das bandas do vermelho, verde e infravermelho próximo da imagem TTC01642.TIF. A curva referente à banda do vermelho mostra uma grande quantidade $\left(\sim 10^{5}\right)$ de pixels saturados para o preto.

Tabela 1 - Valores de saturação para preto e branco para um conjunto de 100 imagens.

\begin{tabular}{c|c|c|c|c}
\hline & \multicolumn{3}{|c}{ Saturação [\%] } \\
\hline CPF padrão & Branco (255) & Preto (0) & Branco (255) \\
\hline Verde & Preto (0) & $4,08 \times 10^{-4}$ & $3,09 \times 10^{-7}$ & $2,35 \times 10^{-4}$ \\
\hline Vermelha & $3,09 \times 10^{-7}$ & $2,59 \times 10^{-4}$ & 0,43 & $5,16 \times 10^{-4}$ \\
\hline IVP & 6,14 & 0,15 & $2,47 \times 10^{-6}$ & $8,41 \times 10^{-2}$ \\
\hline
\end{tabular}

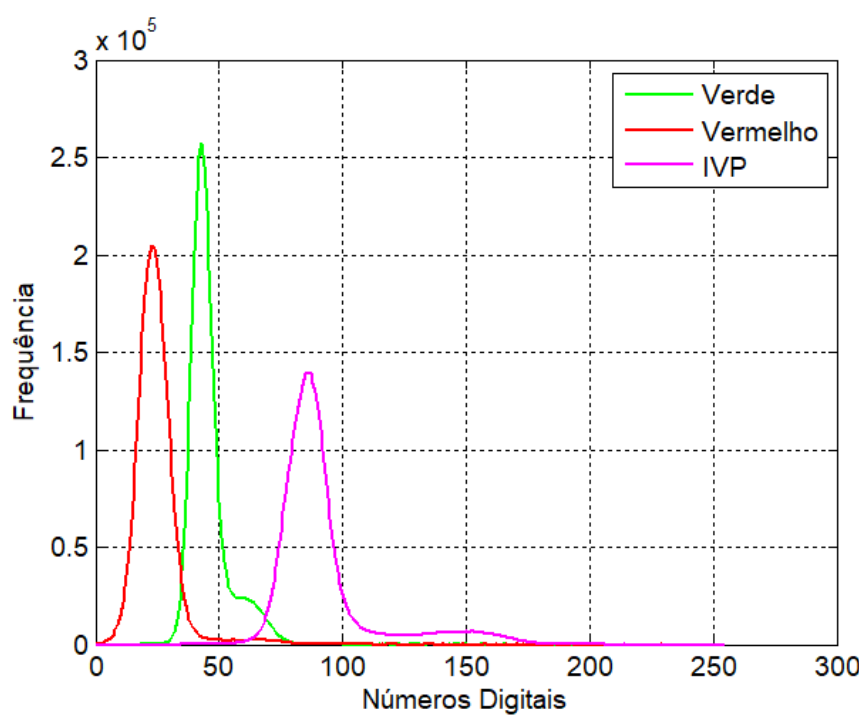

Figura 3 - Histograma das bandas do vermelho, verde e infravermelho próximo da imagem TTC01642.TIF processadas com novo arquivo CPF, mostrando a correção da saturação para preto na banda do vermelho.

Comparando-se com a figura 2, nota-se a correção completa do efeito de saturação na banda do Vermelho. A negligência deste efeito produz consequências diretas na análise dos alvos nas imagens, em que razões normalizadas entre bandas são utilizadas para calcular índices de presença de vegetação verde e sadia. As análises seguintes, relacionadas a distorções radiométricas causadas pelo sensor CMOS da ADC, serão feitas sobre imagens processadas com o novo arquivo de interpolação. 


\section{DISTORÇÕES RADIOMÉTRICAS}

\section{Distorções no Processo de Interpolação}

Como resultado da utilização do filtro de Bayer para, a partir de um único sensor em formato matricial, obtenção das bandas do verde, vermelho e infravermelho próximo, alguns pixels precisam ter seus valores estimados por interpolação. As imagens em formato bruto $(R A W)$ adquiridas pela ADC devem ser processadas no software proprietário PixelWrench2 (PW2) para geração das composições coloridas. Nas imagens resultantes nota-se a presença de pixels que não foram interpolados nas bordas das imagens, mais especificamente, nas três primeiras e nas três últimas linhas e colunas, conforme mostra a figura 4.

Portanto, nos próximos processamentos, esta correção será empregada e aquelas linhas e colunas deverão ser excluídas das imagens, reduzindo as dimensões das cenas de 1.536 linhas por 2.048 colunas para 1.530 linhas por 2.042 colunas.

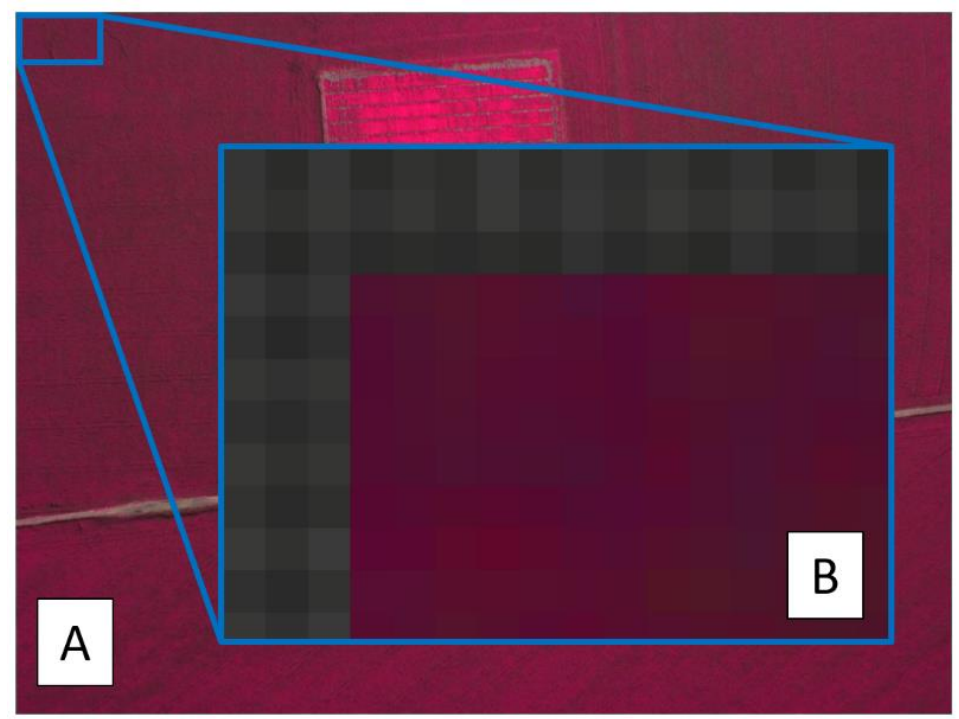

Figura 4 - Imagem TTC01642.TIF (A) e detalhe do canto superior esquerdo (B): artefatos nas bordas das imagens, causados no processo de interpolação do filtro de Bayer. As três primeiras e as três últimas linhas (\#1-3 e \#1534-1536) e colunas (\#1-3 e \#2046-2048) são afetadas e precisam ser descartadas das imagens.

\section{Pixels Defeituosos}

Para além das fontes de distorção já elencadas, existe, ainda, a possibilidade de o sensor apesentar pixels, linhas e colunas (inteiros ou parcialmente) defeituosos. A identificação e correção destes efeitos requer uma análise detalhada dos histogramas das imagens.

Para verificação de possíveis pixels defeituosos do sensor, imagens de uma placa (Figura 5A) de Teflon branca foram adquiridas e analisadas. Foram sete imagens nas quais o campo de visada do sensor foi totalmente ocupado pela placa.

Esta foi iluminada pela radiação solar difusa (irradiância hemisférica). Para reduzir a possível influência de ruídos aleatórios, efetuou-se a média do conjunto de imagens. As imagens foram analisadas visualmente e também quantitativamente com auxílio de seus histogramas.

Visualmente, não foi possível identificar linhas e/ou colunas corrompidas nas imagens. Os histogramas das imagens médias das bandas do Verde, Vermelho e Infravermelho Próximo são mostrados na figura 5B. Nesta, não se percebem quaisquer valores extremos de brilho (mínimos e máximos), e, portanto, pode-se concluir que não existem pixels ruidosos no plano do sensor (após as bordas sem interpolação terem sido descartadas dos dados).

\section{Estimativa do Bias Level, Ganho e Read Noise}

Mesmo quando não exposto, um pixel produzirá uma pequena resposta, uma flutuação probabilística com distribuição ao redor de zero, após o processo de leitura e conversão analógico/ digital (A/D). Esta resposta é conhecida como bias noise. Para evitar valores negativos na imagem de saída a eletrônica do sensor é ajustada para fornecer um valor positivo (offset) para cada imagem. Este valor de offset é chamado de Bias Level. Como exemplo, um bias level típico pode ser um valor de $400 \mathrm{ND}$ (por pixel), que, para um ganho de 10 elétrons/ND, equivale a 4.000 elétrons (Jansen, 2006; Durini, 2014). 
Para correção do bias level são necessárias imagens com tempo de exposição nulo, chamadas de bias frames. Idealmente, o obturador deveria permanecer fechado durante a captura, entretanto, esta tarefa não é possível de ser feita com a ADC. Para contornar este problema, as capturas foram feitas com a objetiva tampada e no menor tempo de exposição possível, que, para o caso, foi $\sim 0,2 \mathrm{~ms}$ ( 1/5.000 s). Estas imagens servirão para estimar não apenas o bias level, mas também o read noise (presente em cada um dos bias frames) e o ganho do CMOS.
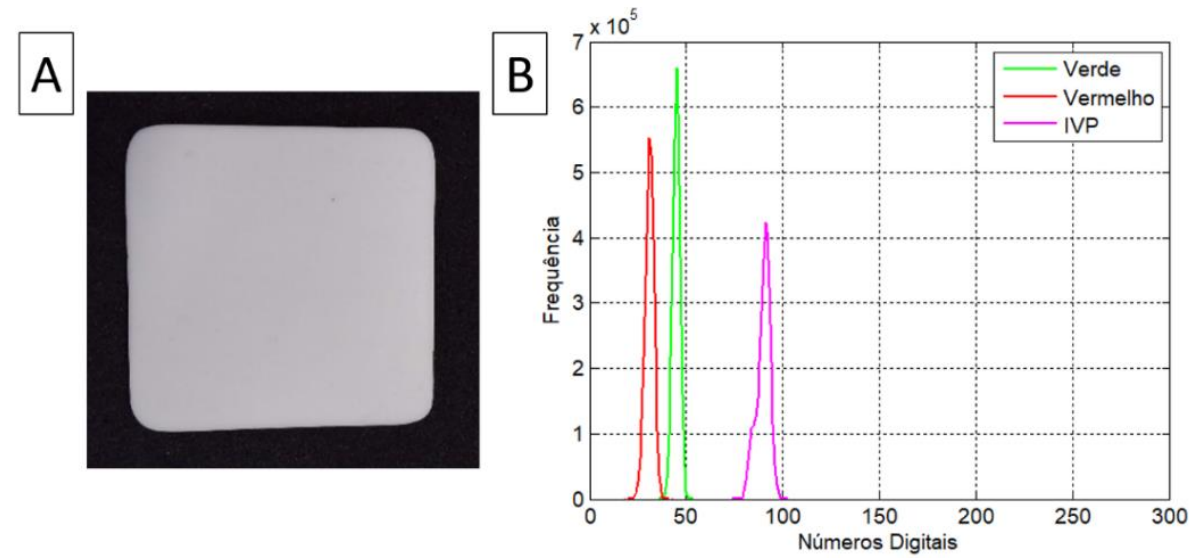

Figura 5 - Placa de Teflon branca (A). Histogramas médios de cada uma das bandas das sete imagens em que o campo de visada do sensor foi totalmente ocupado pela placa (B). As curvas não denunciam valores extremos, que poderiam ser ruídos do sensor.

O Readout noise, ou apenas Read Noise, é definido como a quantidade de elétrons por pixel introduzidos no sinal no momento de sua leitura. Ele é formado por duas componentes inseparáveis: a conversão de analógico para digital (o circuito A/D produzirá uma distribuição estatística de possíveis respostas centradas num valor médio. Portanto, mesmo para o caso hipotético de se ler o mesmo pixel duas vezes, cada uma delas com cargas idênticas, uma resposta diferente pode ser produzida); e a eletronica, que introduz elétrons espúrios no processo, causando flutuações aleatórias no resultado da leitura dos pixels (Howell, 2006; Durini, 2014). $\mathrm{Na}$ imagem resultante, o readout noise é adicionado a cada pixel cada vez que a matiz de detectores é lida. Isso significa que um sensor com um readout noise de 20 elétrons irá, na média, conter 20 elétrons extras em cada pixel após a leitura. Valores aceitáveis de readout noise são de 10 elétrons/pixel por leitura (Jansen, 2006).

$\mathrm{O}$ ganho e o read noise do detector podem ser estimados a partir de pares de imagens de bias frames $\left(B_{1}, B_{2}\right)$ e flat frames $\left(F_{1}, F_{2}\right)$, de acordo com o método proposto por Janesick (2001). São chamadas flat frames imagens de superfícies homogêneas, uniformemente iluminadas, com a mesma distribuição espectral que aquelas que serão corrigidas, adquiridas em campo. Para criação dos flat frames, imagens da placa mostrada na figura $5 \mathrm{~A}$ com tempo de exposição de $30 \mathrm{~ms}$ foram adquiridas, com o campo de visada da câmera totalmente ocupado pela placa. De acordo com Janesick (2001) e Jansen (2006) o ganho (Gain) e o read noise (Read) podem ser calculados pelas equações 1-4:

$$
\begin{array}{r}
\Delta F=F_{1}-F_{2}(1) \\
\Delta B=B_{1}-B_{2}(2) \\
\text { Gain }=\frac{\left(\bar{F}_{1}+\bar{F}_{2}\right)-\left(\bar{B}_{1}+\bar{B}_{2}\right)}{\left(\sigma_{\Delta F}^{2}-\sigma_{\Delta B}^{2}\right)} \\
\text { Read }=\operatorname{Gain} \cdot \frac{\sigma_{\Delta B}}{\sqrt{2}}
\end{array}
$$

Em que $\bar{F}_{i}$ e $\bar{B}_{i}$ são os valores médios, em unidades de ND, dos pares de bias frames e flat frames. O ganho Gain é dado em unidades de $e^{-} / N D$ e o read noise Read em $e^{-}$.

Os bias frames $\left(B_{1}, B_{2}\right)$ contém o bias level e o read noise, e os flat frames $\left(F_{1}, F_{2}\right)$ contém o bias level, read noise e, possivelmente, o dark current, ruído termal associado a elétrons livres no plano do sensor produzidos pela temperatura do CMOS que, por sua vez, pode estar associada à temperatura do ambiente de operação da câmera ou ao tempo de exposição (teoricamente, quanto maior o tempo de exposição, maior a temperatura no plano do sensor).

A incerteza (em unidades de $e^{-}$) na estimativa do ganho pode ser calculada por (Janesick, 2001):

$$
\sigma_{G}=\operatorname{Gain} \cdot\left(\frac{2}{N_{p x l}}\right)^{1 / 2}
$$

Em que $N_{p x l}$ é o número de pixels da imagem 
utilizados para estimar Gain.

Para as estimativas, foram utilizadas regiões de 100 x 100 pixels nos centros das imagens, a fim de evitar variações de brilho em suas extremidades causadas, por exemplo, por vignetting.

Os ganhos foram estimados a partir de três pares de bias frames e flat frames, para cada uma das três bandas. Esta operação resultou em três valores de ganho (um para cada par de bias frame e flat frame) para cada uma das bandas, acompanhados, respectivamente, de suas incertezas calculadas pela equação 5. Estimouse, então, o valor médio de ganho para cada uma das bandas e aplicou-se a propagação de variâncias e covariâncias aos dados a fim de se calcular a precisão final de cada um dos ganhos. Como resultado, os seguintes valores foram estimados: Gain Verde $=28,63 \pm 1,41$ (para a banda do Verde), Gain Vermelho $=17,73 \pm 0,87$ (para a banda do Vermelho) e Gain $_{I V P}=33,40 \pm 1,67$ (para a banda do Infravermelho Próximo), em unidades de $e^{-} / N D$.

Seguindo o mesmo procedimento, o read noise foi calculado usando a equação 4 para três pares de bias frames, um para cada banda. Em seguida, calcularam-se os valores médios de read noise para cada banda e efetuou-se a propagação de variâncias e covariâncias para estimativa da precisão. Os resultados foram: $\operatorname{Read}_{\text {Verde }}=12,59$ $\pm 2,44$, Read $_{\text {Vermelho }}=7,43 \pm 1,52$ e Read $_{I V P}=$ $11,90 \pm 2,89$, em unidades de $e^{-}$.

A partir de 112 imagens de bias frames, com tempo de exposição de $\sim 0,2 \mathrm{~ms}$ cada, calculou-se um master bias frame, obtido da média de todos os bias. O resultado é mostrado na figura 6, para as bandas do Verde (A), Vermelho (B) e Infravermelho Próximo $(\mathrm{C})$, em que são notadas variações de brilho entre as colunas de todas as imagens, conforme previsto para o bias (Howell, 2006).
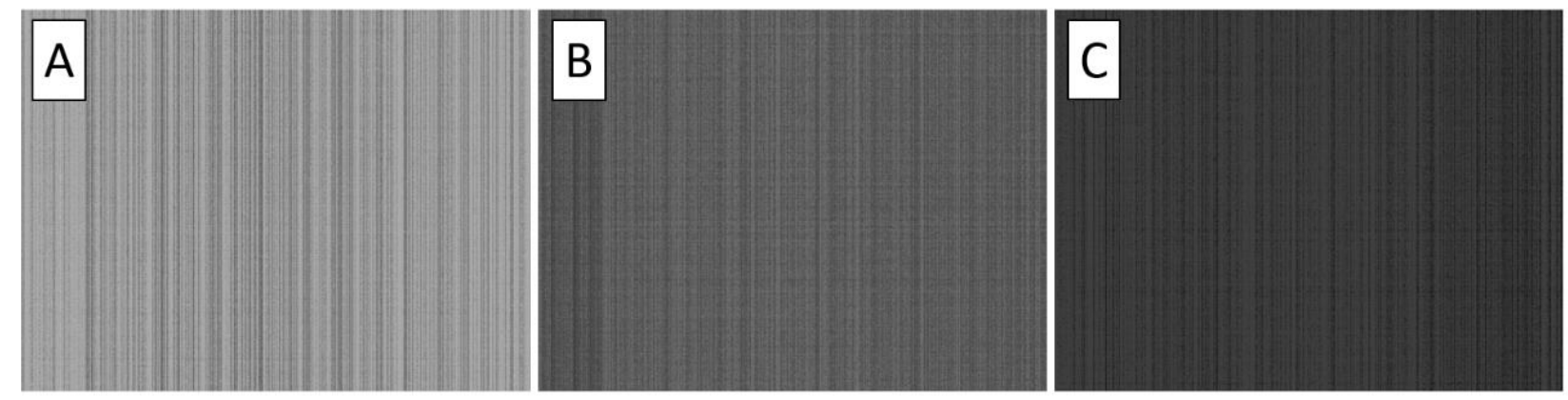

Figura 6 - Master bias frames resultantes da média de 112 imagens de bias: (A) banda do Verde, (B) banda do Vermelho e (C) banda do Infravermelho Próximo.

Na figura 7 são mostrados os níveis digitais médios para cada uma das colunas das três bandas do master bias frame. Sobre cada um dos conjuntos de valores foram ajustados polinômios de grau 7 a fim de identificar pequenas tendências nas variações dos valores médios entre colunas. Da análise da figura 7 é possível perceber uma leve redução nos níveis digitais nas colunas centrais da banda do Verde (Figuras 6A e 7). Na banda do Vermelho percebe-se o escurecimento das colunas 1 a $\sim 400$ e também nas colunas $\sim 2.000$ a 2.042 (Figuras 6B e 7). E, para a banda do Infravermelho Próximo, a variação média para o escuro é mais acentuada nas colunas $\sim 1.600$ a 2.042 (Figuras 6A e 7).

Para o caso das linhas, cujas médias são mostradas na figura 8 , uma variação muito pequena dos valores médios ocorreu na banda do Verde apenas, evidenciando que a variação nos números digitais do master bias frame ocorre predominantemente entre colunas.

A figura 9 mostra os histogramas dos master bias frames para cada uma das bandas. Eles apresentam forma gaussiana, conforme esperado, uma vez que a função densidade de probabilidade do read noise é normal. O valor médio dos histogramas representa o bias level, valor adicionado à toda leitura dos pixels para que o conversor analógico/digital nunca receba valores negativos de contagem de elétrons. A contagem é um processo de estimação, portanto, mesmo quando o sensor não recebe energia eletromagnética, o processo de leitura produzirá uma pequena variação de valores entorno de uma média zero. Assim, a eletrônica do sensor é ajustada para fornecer um valor positivo (offset) para cada imagem, o chamado bias level. Os valores correspondentes aos bias levels de cada uma das bandas são: $B L_{\text {Verde }}=8,79$ $\mathrm{ND}$ (ou 251,66 $e^{-}$), BLVermelho $=12,45 \mathrm{ND}$ (ou $\left.220,74 e^{-}\right)$e $B L_{I V P}=11,88 \mathrm{ND}\left(\right.$ ou $\left.396,79 e^{-}\right)$. 

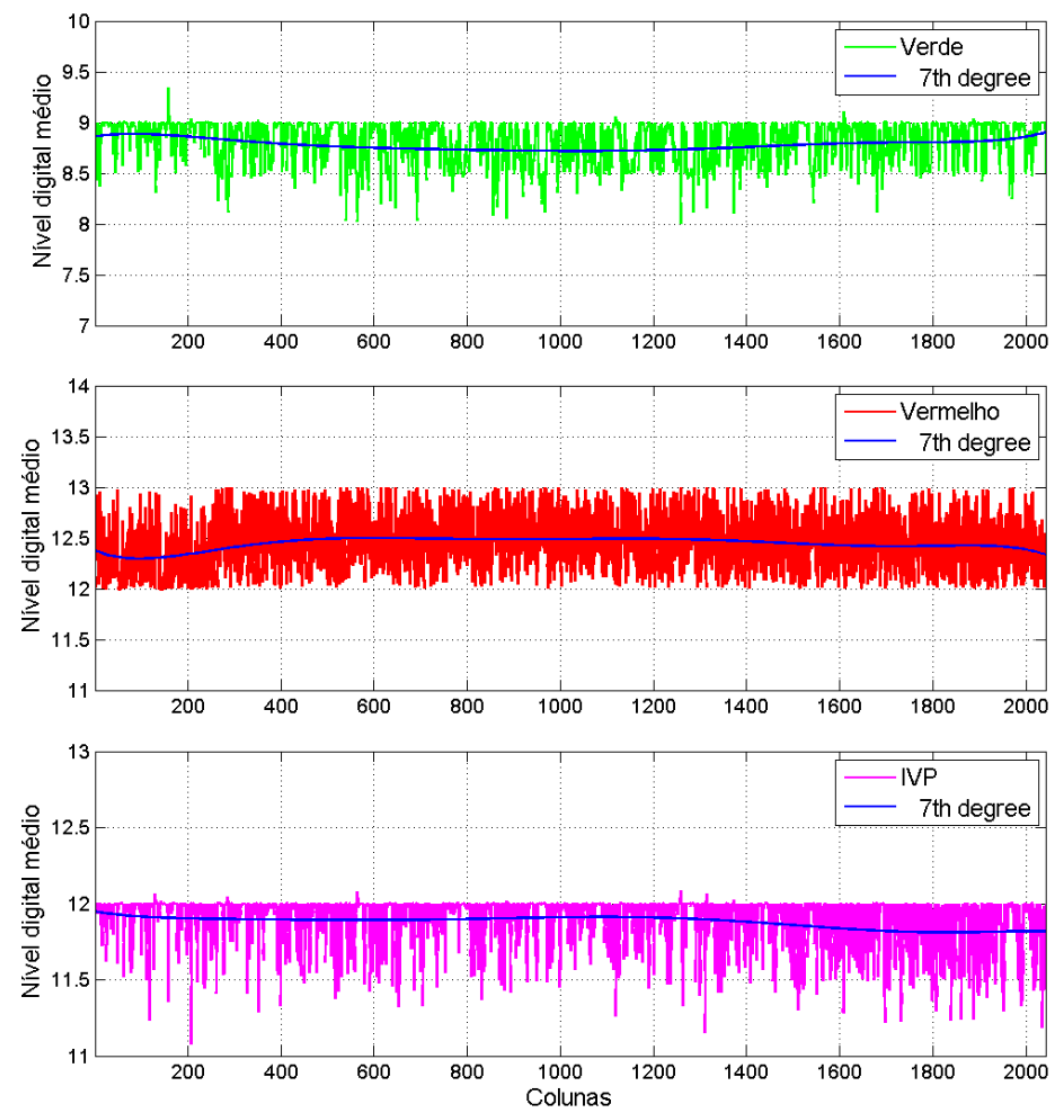

Figura 7 - Valores médios de cada uma das colunas das bandas do Verde, Vermelho e Infravermelho Próximo do master bias frame, evidenciando a não-uniformidade de brilho ao longo da imagem.
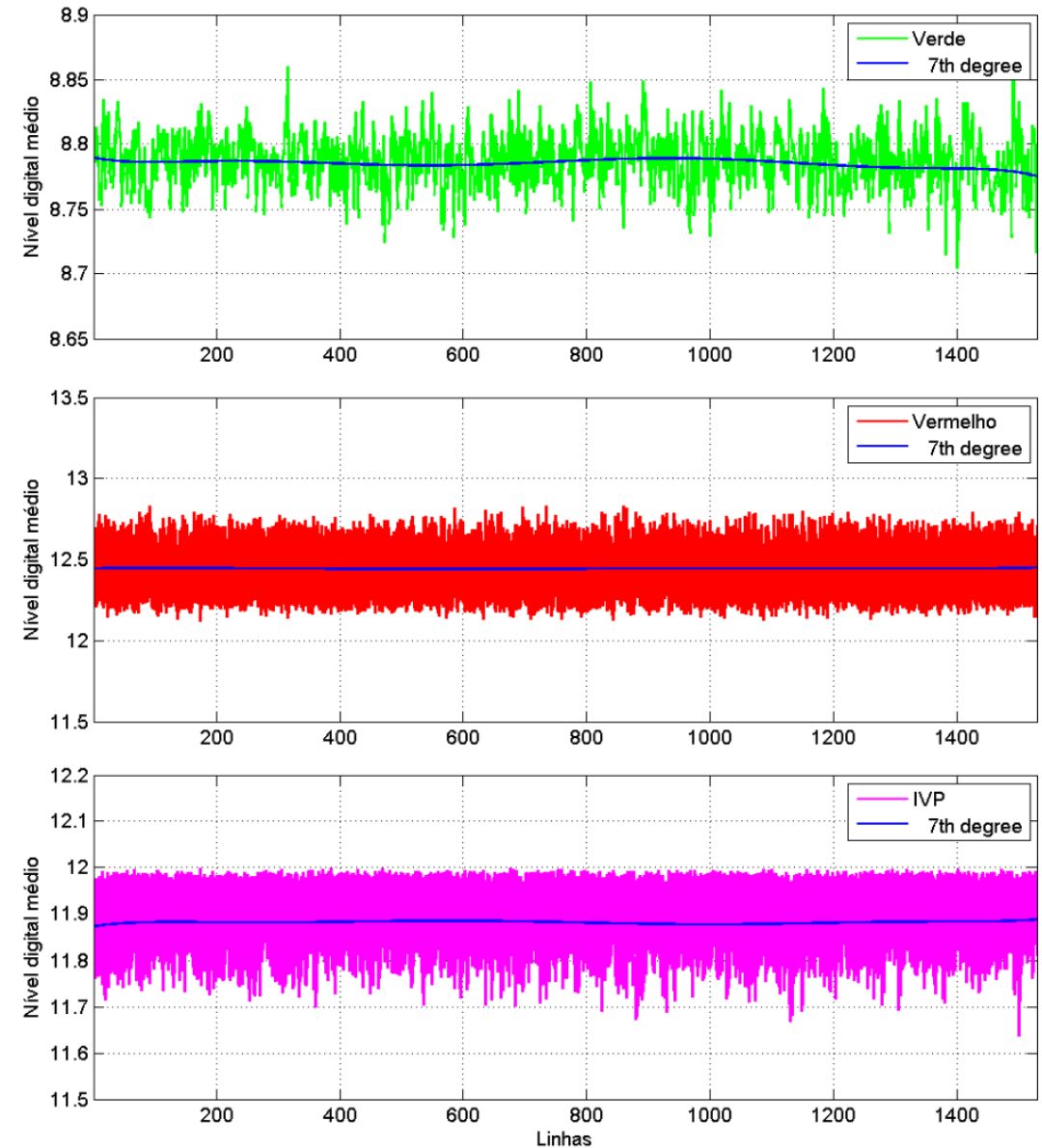

Figura 8 - Valores de brilho médios para as linhas das três bandas do master bias frame. 


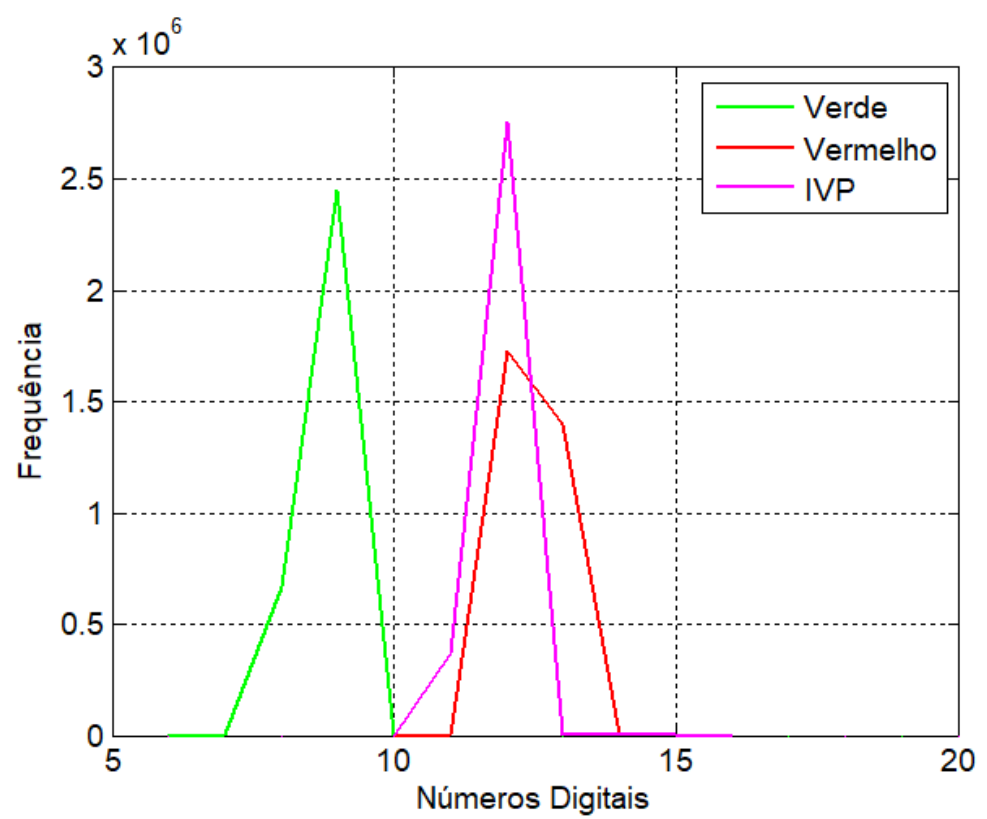

Figura 9 - Histogramas das bandas do verde, vermelho e infravermelho próximo do master bias frame. Seus valores médios representam os bias levels, adicionados para evitar que o conversor analógico/digital receba valores negativos.

Tabela 2 - Valores de bias level, ganho e read noise para as bandas verde, vermelho e infravermelho próximo.

\begin{tabular}{c|c|c|c}
\hline Banda & Bias level $\left[\boldsymbol{e}^{-}\right]$ & Ganho $\boldsymbol{e}^{-} / \boldsymbol{N D}$ & Read noise $\left[\boldsymbol{e}^{-}\right]$ \\
\hline Verde & $\sim 252$ & $\sim 29$ & $\sim 12$ \\
\hline Vermelho & $\sim 221$ & $\sim 18$ & $\sim 9$ \\
\hline Infravermelho próximo & $\sim 397$ & $\sim 33$ & $\sim 11$ \\
\hline
\end{tabular}

Os valores de read noise também podem ser calculados a partir dos histogramas mostrados na figura 9. Eles correspondem ao erro médio quadrático (EMQ) de cada um deles, e resultaram em $E M Q_{\text {verde }}=0,41 \mathrm{ND}$ (ou 11,78 $e^{-}$), $E M Q_{\text {Vermelho }}=0,50 \mathrm{ND}\left(\right.$ ou 8,82 $\left.e^{-}\right)$e $E M Q_{I V P}=$ $0,32 \mathrm{ND}$ (ou 10,78 $e^{-}$). Estes valores estão dentro dos intervalos de precisão calculados via equações 4 e 5 , que são $\sim[10,15] e^{-}$para a banda do Verde, $\sim[6,9] e^{-}$para a banda do Vermelho e $\sim[9,15] e^{-}$para o Infravermelho Próximo, o que confere robustez aos valores estimados. A tabela 2 resume os resultados dos procedimentos realizados.

Ao se analisar os resultados, percebe-se que existe uma discrepância entre o valor de ganho para a banda do Vermelho e para as bandas do Verde e Infravermelho, que são bastante próximos. Diferentemente dos sensores do tipo CCD (Charge Coupled Device), sensores do tipo CMOS, como o que é embarcado na câmera ADC Lite, permitem que a amplificação e ganho sejam aplicados diretamente sobre pixels individuais (na arquitetura CCD a amplificação e ganho são aplicados após a leitura sequencial de linhas da imagem, portanto, neste tipo de sensor estes parâmetros são iguais para todas as células da imagem).
Isso permitiria, por exemplo, a utilização de ganhos diferentes para cada uma das bandas (a depender da posição dos pixels na máscara do filtro de Bayer), mesmo que o sensor da ADC seja do tipo matricial único. No presente caso, a banda do Vermelho parece ter sido ajustada para um ganho mais baixo. Isso faz sentido ao se levar em conta que a câmera desenvolvida pela Tetracam foi pensada para aplicações em agricultura. A reflectância da vegetação verde e sadia na faixa que vai de $\sim 0,6$ a $\sim 0,7 \mu \mathrm{m}$ (Vermelho) é bastante baixa se comparada à reflectância na faixa de $\sim 0,7 \quad$ a $\sim 0,9 \mu \mathrm{m}$ (Infravermelho Próximo).Na região do espectro eletromagnético correspondente a $\sim 0,5$ a $\sim 0,6$ $\mu \mathrm{m}$ (Verde), a reflectância das plantas também será maior que na faixa do Vermelho. Consequentemente, é razoável que o ganho na banda do Vermelho seja menor, fazendo com que se necessitem de menos fótons para produzir uma imagem nesta banda. Seguindo o mesmo raciocínio, isso também explica o valor levemente menor de ganho da banda do Verde em relação à do Infravermelho Próximo.

Com base nas figuras 6 e 7, nota-se que a variação do bias level e read noise nas três bandas produz uma estrutura bidimensional. É desejável, portanto, que, para a correção das 
imagens de campo considere-se subtrair, pixel a pixel, as imagens de bias frame das imagens adquiridas pela ADC.

\section{Análise do Ruído Termal}

A seguir, investigou-se a possibilidade de ocorrência de ruído termal, associado à temperatura do silício. Uma vez que todo material a uma temperatura acima de $0^{\circ} \mathrm{K}$ emite radiação eletromagnética, o detector, ao aquecer, produzirá, também elétrons que serão integrados àqueles oriundos da radiância dos alvos. Em geral, quanto maior o tempo de exposição, maior o aquecimento do CMOS. Este efeito, o dark current, é geralmente especificado em número de elétrons termais gerados por segundo e por pixel. À temperatura de $25^{\circ} \mathrm{C}$, o dark current típico gira em torno de $2,5 \cdot 10^{4} e^{-} / \mathrm{pixel} / \mathrm{s}$. Este componente tem distribuição de Poisson, portanto, o ruído introduzido por elétrons termais no sinal corresponde à raiz quadrada da corrente escura (Howell, 2006). Como exemplo, uma determinada câmera pode ter a especificação de

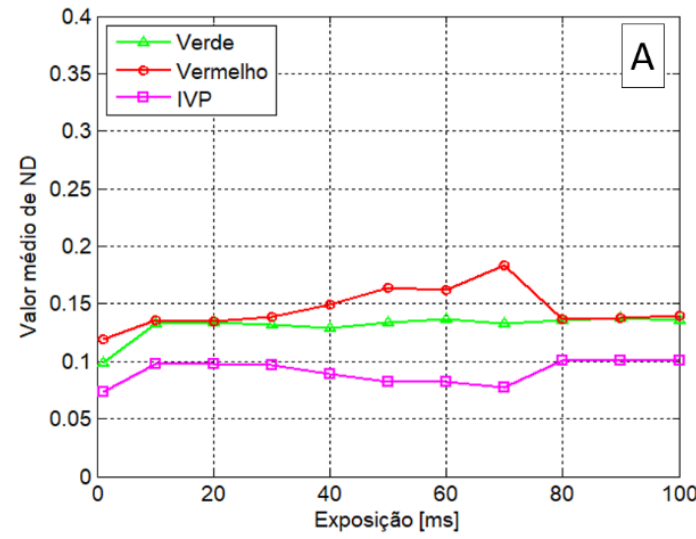

um dark current de $1 e^{-} /$pixel/s. Para uma exposição de $4 \mathrm{~s}$, um total de $4 e^{-} /$pixel são gerados. $\mathrm{O}$ dark current noise é, portanto, a raiz quadrada daquele valor, isto é, $2 e^{-} /$pixel (Howell, 2006).

Para analisar a possível presença de dark current na ADC duas séries de imagens em diferentes tempos de exposição e com a tampa da objetiva fechada foram adquiridas. A primeira série teve seus tempos de exposição variando de $1 \mathrm{~ms}(1 / 1.000 \mathrm{~s})$ até $100 \mathrm{~ms}(1 / 10 \mathrm{~s})$, a intervalos de $10 \mathrm{~ms}(1 / 100 \mathrm{~s})$. A segunda série teve tempos de exposição variando de $100 \mathrm{~ms}$ até $1.000 \mathrm{~ms}$ (1 s) a intervalos de $100 \mathrm{~ms}$. Para cada tempo de exposição foram adquiridas três imagens, totalizando 60 cenas. A média aritmética de cada trio de imagens adquiridas com mesmo tempo de exposição resultou em um master dark frame para a respectiva exposição. Em seguida, subtraiu-se de cada master dark frame seu respectivo master bias frame (eliminando, assim, os efeitos do bias level e read noise de cada imagem).

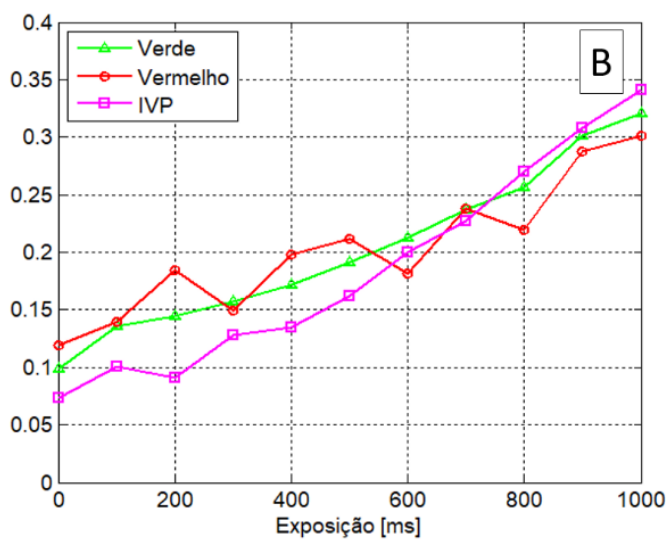

Figura 10 - Valores médios de números digitais (ND) de cada master dark em função de seus tempos de exposição. A influência do tempo de exposição na produção de elétrons espúrios no espectro de operação da ADC pode ser negligenciada.

A figura 10 exibe os valores médios de números digitais de cada master dark frame em função de seus tempos de exposição. No intervalo $[0,100] \mathrm{ms}$ (Figura 10A) não se pode perceber qualquer tendência de aumento nos valores médios de brilho. No intervalo de [0, 1000] ms (Figura 10B) nota-se que, embora pequenos os valores médios, as funções são crescentes no intervalo. Convertendo o valor máximo de $\sim 0,35$ ND (Figura 10B) para elétrons (utilizando os ganhos de cada banda), chega-se aos seguintes resultados de dark current: $\sim 10 e^{-} / \mathrm{s}$ para a banda do Verde, $\sim 6$ $e^{-} / s$ para a banda do Vermelho e $\sim 12 e^{-} / \mathrm{s}$ para a banda do Infravermelho próximo. Estes valores são muito pequenos, não foram suficientes para produzir o aumento de $1 \mathrm{ND}$ e podem ser negligenciados no tratamento das imagens. Tempos de exposição maiores não foram testados uma vez que, para a aerofotogrametria, $1.000 \mathrm{~ms}$ já é considerado um tempo extremamente longo. O arrasto causado pelo movimento da plataforma num caso destes tornaria as imagens inutilizáveis para a finalidade a que se destinam, mesmo com a utilização de câmeras com estabilização do eixo óptico.

\section{Correção de Não-Uniformidade e Vignetting}

Idealmente, cada detector na matriz do CMOS deveria reproduzir a mesma relação linear entre radiância e número digital (ND). Por causa de variações no ganho de cada pixel (ou da não-linearidade das funções de transformação) isso não ocorre. Além disso, 
outros fatores, como sujeira no plano do sensor, podem produzir variações de brilho indesejáveis e irreais em imagens de alvos que apresentam reflectância homogênea. Esse efeito pode ser corrigido por meio de um procedimento conhecido como Flat Fielding. Ele consiste em se adquirir imagens (flat frames) de alvos espacialmente $\mathrm{e}$ espectralmente homogêneos, sob iluminação uniforme, por uma fonte de luz estável e de resposta espectral idêntica àquela usada na tomada das imagens de campo (object frames). Uma opção, então, é dividir as imagens de campo pelo flat frame para corrigir a não uniformidade entre pixels (Jansen, 2006; Schott, 2007). Uma alternativa é fazer o produto da imagem de campo pela razão entre o valor médio do flat e a própria imagem de flat field, conforme a equação 6 :

$$
I_{C}=I \cdot \frac{F_{m}}{F}
$$

Em que $I_{C}$ é a imagem corrigida, $I$ é a imagem a corrigir, $F$ é o flat field e $F_{m}$ é seu valor médio.

Além dos efeitos relatados, o processo de flat fielding também é empregado na correção do vignetting. $\mathrm{O}$ vignetting é o escurecimento radial das imagens em direção às bordas. Ele pode ser causado por diversos fatores, como o bloqueio mecânico da radiação eletromagnética por adaptadores de lentes, efeitos ópticos causados pela combinação de vários elementos de lentes, etc. Quando não modelado e corrigido individualmente, o vignetting é eliminado no processo de flat fielding. A figura 11 exibe os flat frames criados para as bandas do Verde (Figura 11A), Vermelho (Figura 11B) e Infravermelho próximo (Figura 11C). As imagens foram adquiridas sob iluminação difusa, com distribuição espectral semelhante à das imagens de campo. Os desvios padrão de cada flat foram: $\sigma_{\text {flat } G}=1,9 \mathrm{ND}, \sigma_{\text {flatR }}=2,3 \mathrm{ND}$ e $\sigma_{\text {flat } I V P}=$ 3,5 ND.
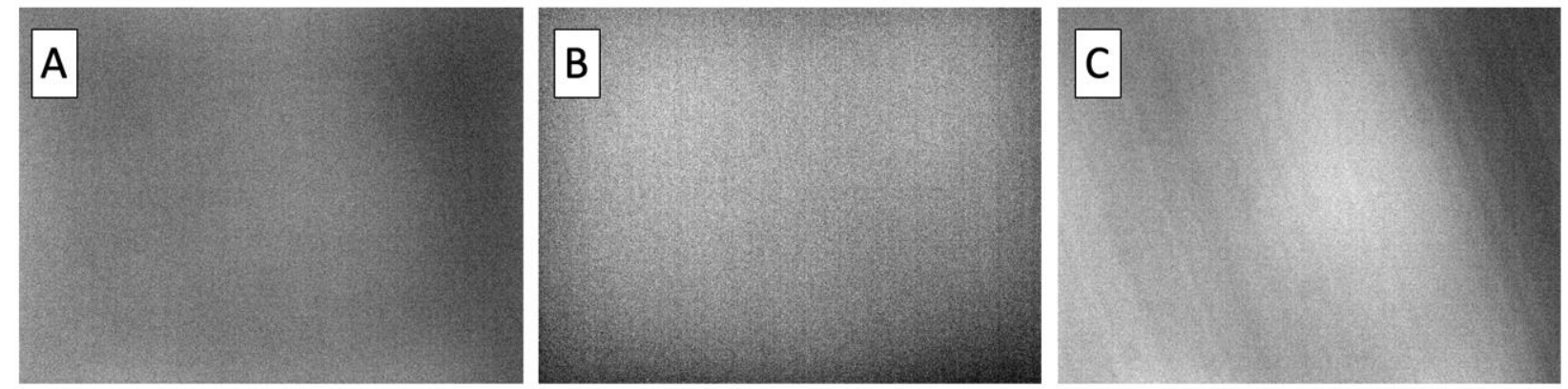

Figura 11 - Flat frames para as bandas do Verde (A), Vermelho (B) e Infravermelho Próximo (C).

$\mathrm{Da}$ análise da figura 11 percebe-se que a resposta dos pixels não é homogênea sobre o plano da imagem. Há uma acentuada variação de brilho em direção às bordas das cenas, num efeito combinado entre vignetting e resposta não uniforme dos detectores.

$\mathrm{Na}$ banda do Verde a variação é mais acentuada no canto superior direito. $\mathrm{Na}$ banda do Vermelho, percebe-se forte presença de vignetting, especialmente na parte inferior do plano da cena. E, na banda do Infravermelho próximo, a variação acentua-se em direção à porção direita e ao canto superior do plano da imagem. A figura 12 exibe o histograma da imagem de campo TTC01642.TIF após o processo de flat fielding.

Com a finalidade de demonstrar o impacto dos valores saturados nas bandas das imagens sem correção, bem como das bordas sem interpolação, efetuou-se uma razão normalizada (RN) entre bandas do Vermelho e Infravermelho Próximo das cenas, da seguinte maneira:

$$
R N=(I V P-\text { Vermelho }) /(\text { IVP }+ \text { Vermelho })(7)
$$

Em que IVP e Vermelho são os valores de brilho em unidades de ND naquelas bandas. No caso em que parâmetros de calibração radiométrica da câmera estivessem disponíveis, os valores de ND deveriam ser convertidos em quantidades físicas de radiância espectral (em unidades de $\mathrm{Wm}^{-2} \mathrm{sr}^{-}$ $\left.{ }^{1} \mu \mathrm{m}^{-1}\right)$ e, posteriormente, convertidos em unidades de reflectância espectral, a partir de medidas de fluxo incidente de radiação eletromagnética sobre os alvos em campo, utilizando-se, por exemplo, de medias de radiância sobre as placas de Teflon ou de espectrorradiômetros. 


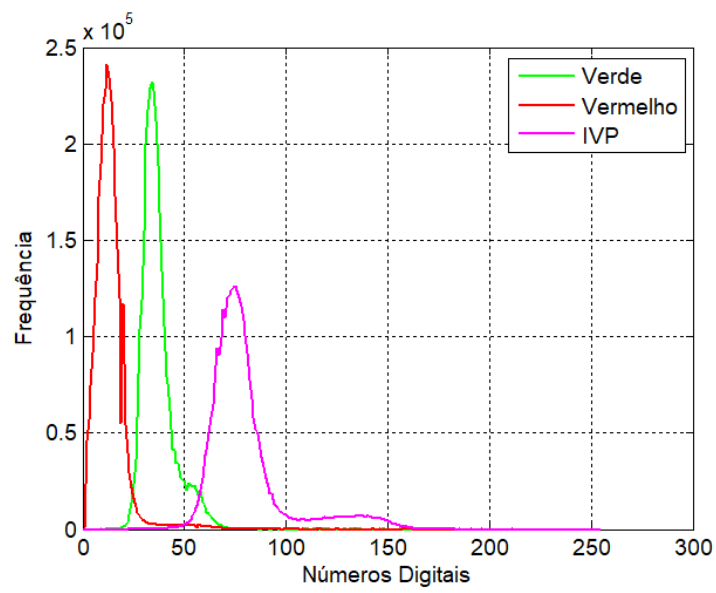

Figura 12 - Histograma das bandas do Verde, Vermelho e Infravermelho Próximo da imagem TTC01642.TIF após o procedimento de flat fielding.

Nesta situação, a razão normalizada dada na equação (7) seria o Índice de Vegetação da Diferença Normalizada (NDVI, no inglês). Como não se dispõe de parâmetros de calibração radiométrica, a equação (7) será tratada apenas como Razão Normalizada. Apesar da não utilização de reflectâncias espectrais para seu cálculo, espera-se que a equação (7) produza valores com variação no intervalo $[-1,1]$, e que ela indique a presença de vegetação sadia com valores próximos de 1 . Valores menores, entre 0 e 0,5 , normalmente são característicos de solo exposto, enquanto valores negativos podem indicar a presença de corpos d'água e/ou

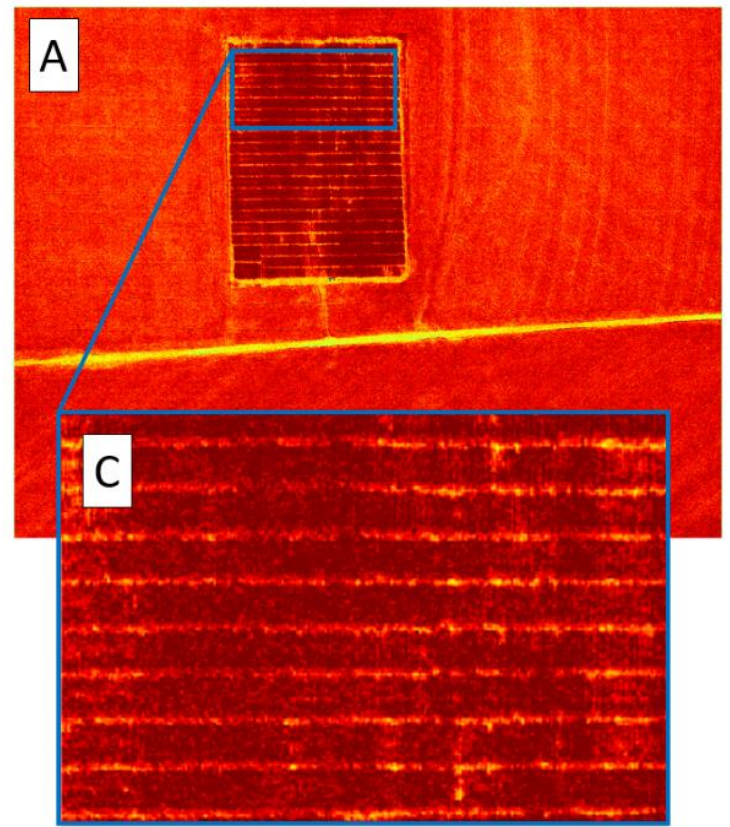

sombras, classes que não ocorrem no presente exemplo.

A figura 13 mostra os resultados obtidos para a razão normalizada entre bandas.

Nas figuras $13 \mathrm{C}$ e 13D, são apresentados recortes ampliados de porções das imagens ocupadas pela cultura de algodão. Visualmente, é possível perceber que, para a imagem sem correção, os valores de RN são superestimados sobre a cultura. De fato, os valores máximos e mínimos para cada um dos índices são: $\mathrm{RN}_{\min }=-$ 0,4 e $R_{\max }=1$ para a imagem sem correção; e $\mathrm{RN}_{\min }=-0,5$ e $\mathrm{RN}_{\max }=0,9$ para a imagem corrigida.

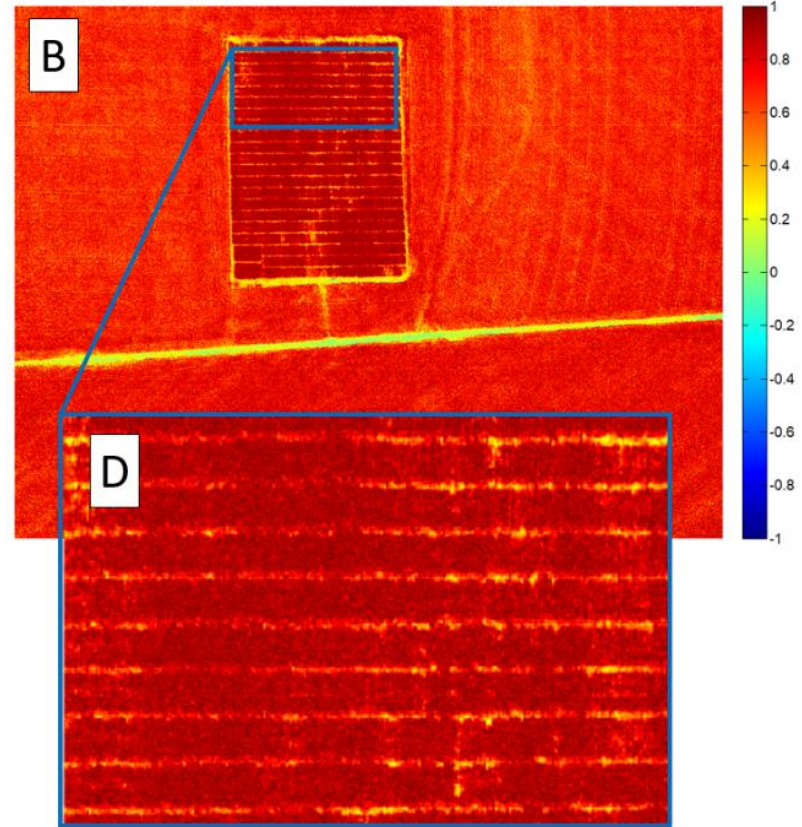

Figura 13 - Razão normalizada entre as bandas do Infravermelho Próximo e do Vermelho da imagem TTC01642.TIF. (A) e (C): a partir da imagem sem correção; (B) e (D): a partir da imagem corrigida.

Além disso, a tabela 3 mostra as porcentagens de pixels da RN agrupados em classes no intervalo $[0,1]$, com amplitude de classe igual a
0,2 , em que se percebe uma quantidade maior $(\sim 3 \%)$ de pixels no intervalo $0,8-1,0$ para o caso das imagens sem correção. 
Os valores superestimados para $\mathrm{RN}$ sem correção foram produzidos, dentre outros fatores, pela saturação para preto na banda do Vermelho, o que força a equação (7) a dar o resultado máximo 1 para o índice.

$\mathrm{Na}$ prática, este resultado é irreal e leva a interpretações errôneas sobre estimativas de biomassa e vigor vegetal da cultura, bem como de incidência de anomalias do crescimento e desenvolvimento das plantas causadas por déficits de nutrientes, humidade e/ou pela presença de pragas.

Nesta área de estudo em particular, a plantação de algodão estava infestada com nematoides. Esta doença provoca alterações na estrutura do mesófilo esponjoso das plantas, provocando uma redução da reflectância na faixa do IVP (Galbieri et al., 2016) e, portanto, os valores de $\mathrm{RN}$ encontrados na figuras $13 \mathrm{~A}$ e $13 \mathrm{C}$ não deveriam ser máximos. Nos casos em que é feita a calibração radiométrica dos dados e radiância ou reflectância podem ser estimadas, a diferença esperada entre os dados brutos e calibrados seria ainda maior. A altura de voo da imagem foi de $100 \mathrm{~m}$, e considerou-se que, para este caso, possíveis efeitos atmosféricos são negligenciáveis. Entretanto, para alturas maiores e para casos em que se pretenda fazer a comparação entre cenas adquiridas em alturas diferentes, uma investigação sobre efeitos de espalhamento e absorção atmosféricos seria necessária.

Tabela 3 - Porcentagem de pixels de razão normalizada para a cena corrigida e para a cena sem correção radiométrica.

\begin{tabular}{c|c|c}
\hline Classe & Razão corrigida [\%] & Razão sem correção [\%] \\
\hline $0,0-0,2$ & $\sim 1$ & 0 \\
\hline $0,2-0,4$ & $\sim 1$ & $\sim 1$ \\
\hline $0,4-0,6$ & $\sim 15$ & $\sim 12$ \\
\hline $0,6-0,8$ & $\sim 58$ & $\sim 58$ \\
\hline $0,8-1,0$ & $\sim 25$ & $\sim 28$ \\
\hline
\end{tabular}

\section{CONCLUSÃO}

Neste artigo abordou-se a análise e correção de distorções radiométricas em imagens do sensor CMOS embarcado na câmera ADC Lite, de fabricação da Tetracam. A ADC é uma câmera multiespectral com sensor matricial único, que se vale de um filtro padrão Bayer para obter imagens nas bandas do Verde, Vermelho e Infravermelho Próximo.

Os valores de brilho faltantes de cada banda são interpolados com base em um arquivo fornecido pela Tetracam. Como demonstrado na seção 3, nem sempre as interpolações com os pesos provenientes deste arquivo produzirão resultados satisfatórios. Sugere-se que, para cada modelo, estudos sejam feitos para se quantificar a saturação das imagens e, caso necessário, que novos arquivos sejam criados. As distorções causadas no processo de leitura da matriz de detectores e posterior conversão $\mathrm{A} / \mathrm{D}$, embora não significativas, devem também ser quantificadas e corrigidas. $\mathrm{O}$ aumento no tempo de exposição não resultou em um dark current significativo para o presente modelo de câmera, podendo ser negligenciável. Já a análise dos flat frames mostrou que existe uma severa variação de brilho no plano de cada banda, com efeitos combinados de não uniformidade de resposta de pixels e vignetting.

As imagens precisam passar então pelo processo de flat Fielding a fim de se eliminar estas distorções. Finalmente, fica evidente, pela análise da figura 13, que a negligência às distorções radiométricas da ADC acarretam erros na interpretação de índices obtidos da razão de bandas. Qualquer aplicação científica séria deverá, consequentemente, estabelecer um protocolo de correções a serem aplicadas às imagens da Tetracam ADC Lite sob pena de os resultados obtidos da análise de suas imagens serem largamente enviesados.

\section{REFERÊNCIAS}

AGUERRA, F.; CARVAJAL, F.; PÉREZ, M. Measuring Sunflower Nitrogen Status From An Unmanned Aerial Vehicle-Based System and on the Ground Device. In: International Archives of the Photogrammetry, Remote Sensing and Spatial Information Sciences, v. XXXVIII1/C22, 2011.

DURINI, D. Fundamental Principals of Photosensing. In: DURINI, D. (ed.) High Performance Silicon Imaging.
Cambridge: Ed. Elsevier, p. 1-24, 2014.

GALBIERI, R.; VAZ, C.M.P.; ASMUS, G.L.; CRESTANA, S.; MATOS, E.S.; MAGALHÃES, C.A.S. Influência de parâmetros de solo na ocorrência de fitonematoides. In: GALBIERI, R. \& BELOT, J.L. (Eds), Nematoides fitoparasitas do algodoeiro nos cerrados brasileiros: Biologia e medidas de controle. Cuiabá: Instituto Matogrossense do Algodão-IMAmt, p. 37-89, 2016. 
GEHRKE, R. \& GREIWE, A. MULTISPECTRAL IMAGE CAPTURING WITH FOVEON SENSORS. Multispectral Image Capturing with Foveon Sensors. In: International Archives of the Photogrammetry, Remote Sensing and Spatial Information Sciences, Volume XL-1/W2, 2013 UAVg2013, 2013.

GONZALEZ, R. C. \& WOODS, R. E. Processamento de Imagens Digitais. Edgard Blucher Ltda. 624 p., 2007.

HOWELL, S.B. Handbook of CCD Astronomy. 2 ed. Cambridge: Cambridge University Press, 218 p., 2006.

HUANG, Y.; THOMSON, S.J.; LAN, Y.; MAAS, S.J. Multispectral Imaging Systems for Airborne Remote Sensing to Support Agricultural Production Management. International Journal of Agricultural and Biologic Engineering. v. 3. n. 1, p. 1-13, 2010.

JANESICK, J. R. Scientific charge-coupled devices. Washington: SPIE, 921 p., 2001.

JANSEN, RA. Astronomy with Charged Coupled Devices. AST 598 Instrumentation and Data Reduction Course. ASU, 199 p., 2006.

MATESE, A.; TOSCANO, P.; DI GENNARO, S.F.; GENESIO, L.; VACCARI, F.P.; PRIMICERIO, J.; BELLI, C.; ZALDEI, A.; BIANCONI, R.; GIOLI, B. Intercomparison of UAV, Aircraft and Satellite Remote Sensing Platforms for Precision Viticulture. Remote Sensing, v. 7. p. 2971-2990, 2015.

MENESES, P.R. \& NETTO, J.S.M. Sensoriamento Remoto: reflectância de alvos naturais. Brasíla: Ed. UnB, 262 p., 2001.
PRIMICERIO, J.; DI GENNARO, S.F.; FIORILLO, E.; GENESIO, L.; LUGATO, E.; MATESE, A.; VACCARI, F.P. A flexible unmanned aerial vehicle for precision agriculture. Precision Agriculture, v. 13. p. 517-523, 2012.

RICHARDS, J. A. Remote Sensing Digital Image Analysis: an introduction. Berlin: Springer, 494 p., 2013.

SCHOTT, J.R. Remote Sensing: the image chain approach. 2 ed. New York: Oxford University Press, 701 p., 2007.

TETRACAM inc. Agricultura Digital Camera User's Guide. 2011. Dip.

em: http://www.Tetracam.com/PDFs/ADC\%20Users\%20Guide\%2 0V2.3.pdf. Acessado em: 22 set, 2019.

VEGA, F. A.; RAMÍREZ, F.C.; SAIZ, M.P.; ROSÚA, F.O. Multi-temporal imaging using an unmanned aerial vehicle for monitoring a sunflower crop. Biosystems Engineering, v. 132. p. 19-27, 2015.

XAVIER, T.W. F., SOUTO, R.N.V., STATELlA, T., GALBIERI, R., SANTOS, E. S., SULI, G.S., ZEILHOFER, P. Identification of Ramularia Leaf Blight Cotton Disease Infection Levels by Multispectral, Multiscale UAV Imagery. Drones. v. 3. n. 33. p. 1-14, 2019.

Submetido em 30 de setembro de 2019 Aceito em 18 de fevereiro de 2020 